\title{
Os fundamentos para a reforma total das decisões recursais proferidas em processos de auto de infração sanitária em portos, aeroportos e fronteiras
}

The fundamentals for the complete reform of appeal decisions pronounced at sanitary infractions proceedings in ports, airports and borders

Los fundamentos para la reforma total de las decisiones proferidas en recurso en procesos de auto de infracción sanitaria en puertos, aeropuertos y fronteras

Anna Luísa Zago Lóes de Albuquerque ${ }^{1}$

RESUMO: Objetivo - Conhecer os principais fundamentos que levaram a Diretoria Colegiada da Anvisa a decidir, nos anos de 2015 e 2016, pela reforma total da decisão em processos de auto de infração sanitária lavrados em portos, aeroportos e fronteiras. Métodos - Foi realizado estudo exploratório, descritivo-analítico, com análise bibliográfica e documental, desenvolvido a partir da análise das atas das reuniões da Diretoria Colegiada da Anvisa ocorridas nos anos de 2015 e 2016, e dos pareceres da área técnica que subsidiaram tais decisões. Resultados - Os resultados demonstraram que os principais fundamentos para a reforma total das decisões foram: a ausência de individualização da pena, a atipicidade da conduta, a prescrição intercorrente, a ausência de adequada manifestação do servidor autuante, a descrição da conduta de forma genérica, e a ilegitimidade passiva. Conclusões - Observou-se um significativo percentual de processos julgados pela Diretoria Colegiada nos anos de 2015 e 2016 que tiveram suas decisões totalmente reformadas, demonstrando a existência de falhas no procedimento administrativo para a apuração de infrações sanitárias em portos, aeroportos e fronteiras.

Palavras-chave: Infração Sanitária. Decisões. Controle Sanitário de Fronteiras. Controle Sanitário de Portos e Embarcações. Controle Sanitário de Aeroportos e Aeronaves.

ABSTRACT: Objective - To recognize the main fundamentals that lead the Anvisa's Board of Directors to decide, between 2015 and 2016, for the totally reform of the decision at punitive administrative proceeding on sanitary violations at ports, airports and borders. Methods - An exploratory, descriptive-analytical study was carried out with a bibliographic and a documental research, based on the evaluation of records from the Anvisa's Board of Directors meetings occurred in 2015 and 2016 and by the reports from the technical area that based such decisions. Results - The results demonstrate that the main reasons for the complete reformation of the decisions were: absence of specific penalty for each violation in decisions, absence of offensive conduct, prescription, lack of adequate manifestation from the inspector, generic description of the conduct, and passive illegitimacy. Conclusion - A significant percentage of proceedings judged by

\footnotetext{
${ }^{1}$ Farmacêutica e Bacharel em Direito. Especialista em Regulação e Vigilância Sanitária da Agência Nacional de
} Vigilância Sanitária (Anvisa). Brasília/DF. E-mail: anninha.zago@gmail.com 
the Board of Directors between 2015 and 2016 had their decisions completely reformed, demonstrating the occurrence of flaws in the administrative procedure for the investigation of sanitary infractions in ports, airports and borders.

Keywords: Sanitary Infraction. Decision. Sanitary Control of Borders. Sanitary Control of Harbors and Crafts. Sanitary Control of Airports and Aircrafts.

RESUMEN: Objetivo - Conocer los fundamentos principales que llevaron el Directorio Colegiado de ANVISA a decidir, en los años 2015 y 2016, por la reforma total de las decisiones en los procesos de investigación de infracciones sanitarias en puertos, aeropuertos y fronteras. Métodos - Se realizó un estudio exploratorio, analíticodescriptivo, bibliográfico y documental, basado en la análisis de las actas de reuniones del Directorio Colegiado de ANVISA, ocurridas entre los años 2015 y 2016, y del parecer del área técnica que subsidiaron tales decisiones. Resultados - Los resultados demostraron que los principales fundamentos para la reforma total de las decisiones fueron: la ausencia de pena específica para cada infracción, la ausencia de conducta ofensiva, la prescripción, la ausencia de adecuada manifestación del funcionario fiscalizador, la descripción de la conducta de forma genérica, y la ilegitimidad pasiva. Conclusiones - Se observo un porcentaje significativo de procesos juzgados por el Directorio Colegiado, en los años 2015 y 2016, que tuvieron sus decisiones totalmente reformadas, demostrando la existencia de fallas en el procedimiento administrativo para investigación de infracciones sanitarias en puertos, aeropuertos y fronteras.

Palabras-llave: Infracción Sanitaria. Decisiones. Control Sanitario de Fronteras. Control Sanitario de Puertos y Embarcaciones. Control Sanitario de Aeropuertos y Aeronaves.

\section{Introdução}

A execução das ações de vigilância sanitária e de vigilância epidemiológica são atribuídas ao Sistema Único de Saúde pela Constituição da República (1), promulgada em 1988 (artigo 200, II). A vigilância sanitária é conceituada na Lei 8.080/90 (2) como o "conjunto de ações capaz de eliminar, diminuir ou prevenir riscos à saúde e de intervir nos problemas sanitários decorrentes do meio ambiente, da produção e circulação de bens e da prestação de serviços de interesse da saúde", e abrange o controle de bens de consumo e da prestação de serviços que se relacionem, direta ou indiretamente, com a saúde (artigo 6응 $\S 1^{\circ}$ ).

A vigilância sanitária assume especial relevância no controle de áreas fronteiriças em um contexto de globalização, em que o fluxo de pessoas e bens é cada vez maior e as distâncias parecem cada vez mais curtas. A fiscalização sanitária em portos, aeroportos, fronteiras e recintos alfandegados atua como barreira para a contenção da propagação de doenças em escala global, bem como para o controle de bens e 
produtos de interesse à saúde que adentram o território nacional e para a garantia da segurança de viajantes e passageiros, constituindo-se em instrumento fundamental para o exercício da soberania nacional.

Dias ressalta a importância das ações de vigilância em áreas fronteiriças, expondo que, em vista da acelerada expansão dos meios de comunicação e transporte (terrestres, fluviais, marítimos e aéreos), "a atenção do Estado deve ser redobrada, organizando-se serviços de vigilância sanitária ágeis e eficazes que atuem, principalmente, nos portos, aeroportos e fronteiras", de forma a monitorar a saúde dos viajantes e as condições sanitárias de embarcações, aeronaves, mercadorias transportadas, dentre outros (3). Destaca-se que o controle sanitário nos portos, aeroportos e fronteiras visa a proteger, além da saúde da população quanto a riscos relacionados à circulação de bens e pessoas, também a agricultura e os rebanhos contra a disseminação de doenças exógenas, que podem provocar um desequilíbrio na fauna e flora do país e gerar prejuízos econômicos incalculáveis (4).

A Lei 9.782/99 (5) confere à Agência Nacional de Vigilância Sanitária - Anvisa, enquanto órgão de vigilância sanitária federal, a atribuição de execução das atividades de vigilância sanitária em portos, aeroportos e fronteiras, bem como as de vigilância epidemiológica e de controle de vetores, sob orientação técnica e normativa do Ministério da Saúde (artigo $7^{\circ}$, $\S^{\circ}$ ). Atualmente, a estrutura da Anvisa em portos, aeroportos, fronteiras e recintos alfandegados ${ }^{2}$ (classicamente PAF) consiste em dezenas de Postos de controle distribuídos pelo país, todos vinculados a uma das 27 Coordenações de vigilância sanitária estabelecidas nos estados da Federação e no Distrito Federal, as quais são responsáveis por coordenar, acompanhar, avaliar e supervisionar os respectivos Postos.

Aos Postos de Vigilância Sanitária de PAF compete a efetiva fiscalização sanitária das áreas fronteiriças. Oliveira divide tal fiscalização sanitária didaticamente em cinco categorias:

[...] de viajantes (orientação, vacinação, notificação de anormalidades clínicas a bordo), de cadáveres (liberação do translado de restos

\footnotetext{
${ }^{2}$ A Lei no 9.782/1977 submete ao controle sanitário os serviços e instalações relacionados com as atividades de portos, aeroportos e fronteiras e nas estações aduaneiras e terminais alfandegados (artigo 8º, §8ํㅜ). Utiliza-se no presente trabalho corriqueiramente o termo comum mais conhecido "Portos, Aeroportos e Fronteiras" (classicamente PAF); contudo, ressalta-se que o presente estudo engloba também a fiscalização sanitária realizada em terminais alfandegados (zona secundária), por ser esta de competência da Agência Nacional de Vigilância Sanitária.
} 
mortais), de produtos (inspeção de mercadorias sob importação ou exportação), de meios de transporte (inspeção de embarcações, aeronaves e de transportes terrestres) e de ambientes (controle de vetores, de resíduos, de água para uso humano etc.). (6)

A estes, acrescente-se ainda a fiscalização de serviços de interesse à saúde localizados em área de portos, aeroportos e fronteiras, como serviços de alimentação, drogarias e postos médicos.

Para a execução das ações de fiscalização sanitária em PAF, a Anvisa é dotada de competências e prerrogativas que lhe permitem resguardar a saúde da população e dos viajantes. O artigo $7^{\circ}$, XIV, da Lei 9.782/99, ao criar a Agência, atribui-Ihe a competência de "interditar, como medida de vigilância sanitária, os locais de fabricação, controle, importação, armazenamento, distribuição e venda de produtos e de prestação de serviços relativos à saúde, em caso de violação da legislação pertinente ou de risco iminente à saúde".

O artigo 13 do Decreto 8.077/2013 (7), que regulamenta a Lei 6.360/76 (8), prevê que os agentes a serviço da vigilância sanitária, em suas atividades de controle e monitoramento, terão, entre outras, a prerrogativa de interditar, parcial ou totalmente, os estabelecimentos e os lotes de produtos sujeitos à vigilância sanitária em virtude do descumprimento da legislação de saúde aplicável, lavrando-se os respectivos termos (inciso VI), bem como de determinar e fiscalizar a imediata inutilização dos produtos cuja adulteração ou deterioração seja flagrante e apreender ou interditar o restante do lote (inciso VII). Semelhante disposição já existia desde o ano de 1977, conforme o artigo 151 do Decreto 79.094/77 (9), que regulamentava a Lei 6.360/76 e foi inteiramente revogado pelo Decreto 8.077/2013.

Também o artigo 23 da Lei 6.437/77 (10) prevê a possibilidade de interdição de forma cautelar do produto ou do estabelecimento para a apuração de infração sanitária, a qual não pode exceder o prazo de 90 dias, após o qual o produto ou estabelecimento é automaticamente liberado. Ressalte-se que a interdição cautelar referida em citado dispositivo não se confunde com a interdição prevista como penalidade no artigo $2^{\circ}$ da mesma Lei, a qual depende da finalização de processo administrativo sanitário para sua imposição, resguardados o contraditório e a ampla defesa. 
Machado leciona que a interdição cautelar, enquanto medida mais drástica, somente deve se operar em casos de flagrante infração à legislação sanitária e ante a existência concreta de risco de dano à saúde pública, posição esta já firmada em jurisprudência nos tribunais brasileiros (11).

As medidas cautelares ora citadas têm caráter preventivo e visam ao resguardo da saúde da população ante a detecção de irregularidade sanitária que tenha potencial de causar danos à saúde da coletividade. Considerando a prevenção de riscos, que

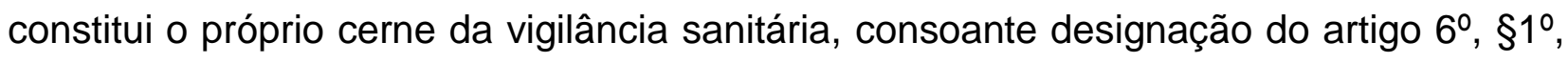
da Lei 8.080/90, incumbe aos agentes de fiscalização sanitária a adoção de ações imediatas que visem impedir a exposição da população a riscos à saúde, ainda que de forma temporária, até que se tenha certeza acerca da segurança do bem ou serviço.

Registre-se que, nos casos relacionados à saúde pública, nos quais se exige ação célere pelo agente público para a contenção de potenciais riscos à saúde da população, a fim de se evitar lesão grave ou de difícil reparação à coletividade, os atos decorrentes do poder de polícia administrativa são dotados de executoriedade (11), esta entendida como "a qualidade pela qual o Poder Público pode compelir materialmente o administrado, sem precisão de buscar previamente as vias judicias, ao cumprimento da obrigação que impôs e exigiu (12)".

Também compete aos Postos de Vigilância Sanitária de PAF a instauração dos processos de contencioso administrativo sanitário (artigo 181, III, do Regimento Interno da Anvisa (13)), os quais são regidos pela Lei $6.437 / 77$, que configura infrações à legislação sanitária federal e estabelece as sanções respectivas, e, subsidiariamente, pela Lei 9.784/99 (14), que regula o processo administrativo no âmbito da Administração Pública Federal. Assim, ante a constatação pelo fiscal da existência de conduta contrária às normas de direito sanitário, passível de tipificação em um dos incisos do artigo 10 da Lei $6.437 / 77$, é instaurado o processo administrativo sanitário para sua apuração.

Bandeira de Mello define o processo administrativo como "uma sucessão itinerária e encadeada de atos administrativos tendendo todos a um resultado final e conclusivo (12)". Moreira descreve ainda o processo administrativo como um "instrumento de 
garantia e satisfação dos direitos individuais celebrados na Constituição e leis infraconstitucionais (15)".

Assim, tem-se o processo administrativo-sanitário como uma espécie do processo administrativo, o qual é instaurado a partir da lavratura do auto de infração sanitária e objetiva a apuração da ocorrência de infração às normas de saúde, observando-se os princípios do devido processo legal, do contraditório e da ampla defesa, consoante artigo 15, LIV e LV, da Carta Magna. Cartana assim conceitua o processo administrativo-sanitário:

O Processo Administrativo Sanitário é o instrumento legal que possibilita a identificação, o enquadramento e a autoria do delito sanitário com vistas à punição individuada e, consequentemente, o restabelecimento da normalidade e da regularidade da coisa, serviço, ambiente ou bem, quanto às condições exigíveis para produção e consumo de bens ou prestação de serviços (16).

O auto de infração sanitária, peça inaugural do processo administrativo que cientifica o autuado acerca da instauração do processo administrativo sanitário para a apuração do ilícito, possui forma determinada a ser observada pelo agente autuante, consoante determina o artigo 13 da Lei 6.437/77.

Notificado o autuado acerca da lavratura do auto de infração, é-lhe concedido o prazo de 15 dias para a apresentação de impugnação (artigo 22 da Lei 6.437/77), devendo em seguida o servidor autuante se pronunciar a respeito das razões apresentadas (artigo 22, §1ํㅡㄹ da Lei 6.437/77).

O processo segue então para decisão em primeira instância administrativa, podendo a Administração aplicar as sanções previstas nos artigos $2^{\circ}$ e 10 da Lei 6.437/77 em caso de confirmação da autoria e materialidade da infração sanitária, observando-se, dentre outros aspectos, as atenuantes e agravantes, o risco sanitário da conduta descrita no auto de infração, o porte econômico da autuada e seus antecedentes quanto a anteriores condenações por infrações à legislação sanitária.

Cientificado sobre os termos da decisão inicial, é concedido ao autuado o prazo de 20 dias para a interposição de recurso (artigo 30, parágrafo único, da Lei 6.437/77), que é dirigido à autoridade julgadora de primeira instância administrativa para a realização do juízo de reconsideração (artigo 56, §1ํㅡ, da Lei 9.784/99). Não reconsiderada a 
decisão, o processo segue para decisão pela Diretoria Colegiada da Agência como última instância administrativa (artigo 15, VI e §2º , da Lei 9.782/99).

Ainda, em vista do poder de autotutela de que goza a Administração Pública, insculpido no artigo 65, parágrafo único, da Lei 9.784/99, os processos administrativos dos quais resultem sanções "poderão ser revistos a qualquer tempo, a pedido ou de ofício, quando surgirem fatos novos ou circunstâncias relevantes suscetíveis a justificar a inadequação da sanção aplicada". Assim sendo, mesmo que já tenha havido a decisão do processo em última instância administrativa pela Diretoria Colegiada da Agência, é cabível a revisão do processo, a pedido do administrado ou de ofício pela Administração, em caso de verificação de circunstâncias que evidenciem a existência de nulidade.

Nessa esteira, acrescenta-se que o artigo 53 da mesma Lei 9.784/99, mais do que conceder à Administração Pública o poder de autotutela de seus atos, impõe a ela o dever de anulá-los quando eivados de vício de legalidade, sendo a faculdade mantida para os casos de revogação por conveniência ou oportunidade, respeitados os direitos adquiridos. É o que ocorre, por exemplo, nos casos em que é imputada penalidade de multa a empresa como se de grande porte fosse, descobrindo-se ao final do processo que a autuada era, em verdade, empresa de menor porte. Em vista da existência de mandamento legal que determina que seja considerada na aplicação da penalidade de multa a capacidade econômica do infrator (artigo $2^{\circ}$, §3ํㅡㄹ da Lei 6.437/77), resta evidenciada a existência de vício de legalidade, que a Administração tem o dever de prontamente reparar, em respeito ao princípio da legalidade insculpido no artigo 37 da Constituição da República.

Gasparini conceitua a invalidação do ato administrativo como "a retirada retroativa, parcial ou total, de um ato administrativo, praticado em desconformidade com 0 ordenamento jurídico, por outro ato administrativo (17)". No mesmo sentido, Bandeira de Mello define a invalidação como "a supressão de um ato administrativo ou da relação jurídica dele nascida, por haverem sido produzidos em desconformidade com a ordem jurídica (12)".

Sobre os efeitos da invalidação do ato administrativo, assim leciona Gasparini:

Os efeitos do ato de invalidação alcançam o ato administrativo inválido no seu nascedouro, já que não há nulidade superveniente. São, portanto, 
retroativos. Operam desde então, ou ex tunc. Restaura-se, em sua plenitude, a situação vigente anteriormente ao ato invalidado, resguardados unicamente os efeitos que atingiram terceiros de boa-fé (17).

Vê-se, portanto, que a invalidação, ao retirar o ato do ordenamento jurídico, fulmina qualquer efeito que dele tenha decorrido, retroagindo à data do ato inválido e atingindo todos os atos dele decorrentes.

Bandeira de Mello posiciona-se pela possibilidade de haver no Direito Administrativo brasileiro tratamentos distintos dados pelo ordenamento jurídico conforme o tipo de ilegitimidade verificada no ato. Vejamos:

Não há graus na invalidade. Ato algum em Direito é mais inválido do que outro. Todavia, pode haver e há reações do Direito mais ou menos radicais ante as várias hipóteses de invalidade. Ou seja: a ordem normativa pode repelir com intensidade variável atos praticados em desobediência às disposições jurídicas, estabelecendo, destarte, uma gradação no repúdio a eles.

E precisamente esta diferença quanto à intensidade da repulsa que o Direito estabeleça perante os atos inválidos o que determina um discrímen entre atos nulos e atos anuláveis [...].(12)

Conceitua o autor 0 ato nulo como aquele em que é racionalmente impossível a convalidação, pois, se o ato fosse novamente editado com o mesmo conteúdo, persistiria a invalidade anterior; ainda, classifica o ato anulável como aquele que pode ser praticado sem vício (a exemplo dos atos expedidos por sujeito sem competência para tanto ou editados com defeito na forma) (12).

No mesmo sentido entende Carvalho Filho, que admite que um ato administrativo maculado por um vício sem maior gravidade pode ser convertido em ato válido por meio da convalidação, aproveitando-se assim os efeitos inicialmente produzidos. Contudo, apesar de filiar-se à corrente dualista, que admite a existência de atos nulos e anuláveis no Direito Administrativo, ressalta que a regra deve ser a nulidade, somente se admitindo a convalidação em casos excepcionais (18).

Registre-se que o artigo 55 da Lei 9.784/99 dispõe que os atos que apresentem vícios sanáveis poderão ser convalidados pela Administração Pública quando não acarretarem lesão ao interesse público e nem prejuízo a terceiros ${ }^{3}$. A despeito da

\footnotetext{
${ }^{3}$ Art. 55. Em decisão na qual se evidencie não acarretarem lesão ao interesse público nem prejuízo a terceiros, os atos que apresentarem defeitos sanáveis poderão ser convalidados pela própria Administração.
} 
previsão legal quanto à possibilidade de convalidação dos atos pela Administração, no entanto, diversos doutrinadores entendem pela impossibilidade de recepção da teoria dualista.

Gasparini rejeita, com amparo no princípio da legalidade, a possibilidade de separação dos atos administrativos em atos nulos e anuláveis, como ocorre no Direito Privado, por entender que o ato administrativo ilegal sempre ofenderá um interesse público, sendo, portanto, nulo. Afasta ainda a possibilidade de convalidação do ato considerado inválido, admitindo tão somente o reparo de pequenas irregularidades existentes no ato, a exemplo dos erros gráficos (17).

Da mesma forma, posiciona-se Medauar pela insustentabilidade da diferenciação dos tipos de defeitos dos negócios jurídicos previstos no Direito Civil no estudo do Direito Administrativo, uma vez que neste todas as normas são, em princípio, de ordem pública, sendo todos os atos administrativos editados para atendimento do interesse público. Assim, qualquer ato administrativo dotado de vício seria nulo, em princípio (19).

Tal entendimento é partilhado por Meirelles, que rejeita o ato anulável no Direito Administrativo, tendo em vista a preponderância do interesse público sobre o privado e a impossibilidade de manutenção de atos ilegais, ainda que este seja o desejo das partes, uma vez que é a Administração Pública vinculada ao princípio da legalidade (20).

A declaração de nulidade dos atos administrativos quando verificada sua ilegalidade pelo poder público é de suma importância para a efetivação do princípio maior da legalidade, ao qual é submetida a Administração Pública por mandamento constitucional. No caso da apuração de infrações sanitárias por meio de processo administrativo próprio, tem-se de um lado os interesses de toda a coletividade, representados pela Administração Pública, e do outro os interesses do administrado. À Administração Pública cabe o estrito cumprimento da norma, observando sempre a prevalência do interesse público sobre o particular.

Sabidamente, o interesse público é lesado quando, por exemplo, a Administração Pública penaliza o administrado com menor intensidade do que preconiza a lei em razão da constatação de uma infração sanitária. Contudo, da mesma forma o interesse público é lesado quando a Administração o penaliza com maior intensidade do que o legalmente estipulado, imputando-Ihe penalidade de multa superior aos limites legais, por exemplo. 
Ocorre que a efetiva imputação da devida penalidade ao infrator é tão importante quanto à garantia de sua aplicação estritamente nos limites da lei. Assim, não somente o administrado é prejudicado pela imposição de penalidade de multa em valor superior ao legalmente estipulado, como se haveria de supor, mas sim toda a coletividade.

Tem-se, portanto, por indissociável o dever da Administração Pública de anular seus atos quando ilegais do princípio da legalidade consagrado no artigo 37 da Carta Magna, fundamental para a manutenção das garantias do Estado Democrático de Direito.

Nesse sentido, Medauar aponta que, em alguns casos de vícios em atos administrativos, "embora a ilegalidade não acarrete prejuízo direto a pessoas, pode representar lesão a valores indisponíveis que a legislação administrativa quer preservar (19)", uma vez que as normas de direito administrativo muitas vezes visam ao atendimento de valores administrativos, como a moralidade.

Quanto à possibilidade de indenização em decorrência da invalidação de ato administrativo maculado por vício de legalidade, Bandeira de Mello leciona que, nos casos em que a invalidação atinge ato ou relação jurídica em que o administrado já incorreu em despesas por conta delas, e estando o administrado de boa-fé e não tendo concorrido para o vício constatado no ato invalidado, surge o dever da Administração de repará-lo. Tal entendimento decorre da aplicação concreta do artigo 37, §6º, da Constituição Federal, que dispõe acerca da responsabilidade civil do Estado (12). Vejamos:

Com efeito, se 0 ato administrativo era inválido, isto significa que a Administração, ao praticá-lo, feriu a ordem jurídica. Assim, ao invalidar o ato, estará, ipso facto, proclamando que fora autora de uma violação da ordem jurídica. Seria iníquo que o agente violador do Direito, confessando-se tal, se livrasse de quaisquer ônus que decorreriam do ato e lançasse sobre as costas alheias todas as consequências patrimoniais gravosas que daí decorreriam, locupletando-se, ainda, à custa de quem, não tendo concorrido para o vício, haja procedido de boa-fé. Acrescente que, notoriamente, os atos administrativos gozam de presunção de legitimidade. Donde, quem atuou arrimado neles, salvo se estava de má-fé (vício que se pode provar, mas não pressupor liminarmente), tem o direito de esperar que tais atos se revistam de um mínimo de seriedade. Este mínimo consiste em não serem causas potenciais de fraude ao patrimônio de quem neles confiou - como, de resto, teria de confiar (12). 
Também Gasparini entende ser cabível a indenização em decorrência da invalidação de atos administrativos, nos casos em que tiver ocorrido algum investimento ou despesa pelo administrado, desde que verificada a boa-fé do beneficiário (17).

O presente trabalho traz a análise dos principais fundamentos para a reforma total pela Diretoria Colegiada da Anvisa, em sede recursal e revisional, das decisões condenatórias proferidas em processos de auto de infração sanitária lavrados em PAF, bem como faz uma reflexão acerca de seus efeitos e seu impacto na fiscalização sanitária, a partir dos conceitos clássicos do Direito Administrativo de nulidade e anulabilidade dos atos. Tem-se por hipótese que as principais causas para a reforma total das decisões são (a) a interpretação equivocada da norma sanitária pelo agente autuante, (b) a existência de erro formal no preenchimento do auto, e (c) a má instrução processual.

\section{Metodologia}

Trata-se de estudo exploratório, descritivo-analítico, com análise bibliográfica e documental, de caráter quali-quantitativo, desenvolvido a partir da utilização de dados obtidos por meio da análise das atas das reuniões da Diretoria Colegiada da Agência Nacional de Vigilância Sanitária (Anvisa) e dos pareceres da área técnica que subsidiaram a decisão colegiada.

Foram analisadas as atas de julgamento das reuniões (Reunião Ordinária Pública e Reunião Extraordinária) da Diretoria Colegiada da Anvisa, realizadas no ano de 2015 e 2016, a fim de identificar os processos de autos de infração sanitária lavrados em PAF e as respectivas decisões da Diretoria Colegiada que reformaram integralmente as decisões iniciais naqueles anos. Não estando todas as atas disponibilizadas no sítio eletrônico da Agência, foi solicitado à Secretaria Executiva da Diretoria Colegiada o acesso a elas, cuja disponibilização foi feita por meio eletrônico. Os dados obtidos foram tabulados para melhor organização e sistematização.

Identificados os processos cujas decisões iniciais foram totalmente reformadas, foi realizada busca e leitura em inteiro teor dos respectivos Pareceres Técnicos emitidos pela Coordenação da Instrução e Análise de Recursos da Inspeção e Fiscalização - 
CORIF para subsidiar a decisão da Diretoria Colegiada, a fim de verificar os motivos que levaram a Agência a decidir de tal forma.

Foi requerida autorização formal por meio de formulário próprio da Anvisa (Solicitação de informações para fins de trabalhos acadêmicos e de pesquisa) para a utilização dos dados levantados no presente trabalho, com anuência dos responsáveis pela Coordenação da Instrução e Análise de Recursos da Inspeção e Fiscalização CORIF e pela Coordenação de Segurança Institucional - CSEGI.

Foram objeto do presente estudo os processos instaurados a partir da lavratura de autos de infração sanitária em PAF que foram julgados pela Diretoria Colegiada da Anvisa nos anos de 2015 e 2016, tanto em âmbito recursal como em sede revisional (pedido de revisão ou revisão de ofício), a fim de permitir uma melhor análise do posicionamento do colegiado em tais processos. A escolha pela análise dos dados dos processos pela data de sua decisão pela Diretoria Colegiada, e não pela data de lavratura do auto de infração, deu-se em razão da dificuldade em sistematizar tais dados conforme a data de lavratura dos autos, tendo em vista a grande diferença nos tempos que os processos demoram para serem concluídos, especialmente em função das diferentes causas de interrupção da prescrição, nos termos da Lei 9.873/99 (21). A eleição dos anos de 2015 e 2016 para a realização do presente estudo se deu em razão de naquele ano já existir uma Coordenação de Recursos dedicada à análise dos recursos administrativos interpostos contra as decisões de primeira instância nos processos instaurados em PAF.

A fim de permitir a análise dos dados obtidos e a melhor compreensão das repercussões das reformas totais feitas pela Diretoria Colegiada da Anvisa em processos de autos de infração sanitária em PAF, foi realizada revisão bibliográfica sobre o tema em bibliotecas físicas e consulta a livros e obras de referência na área do Direito Administrativo e do Direito Administrativo Sanitário.

O presente estudo não foi submetido ao Comitê de Ética em Pesquisa da Fiocruz Brasília, nos termos da Resolução 510/2016-CNS/MS, uma vez que foi realizado a partir de pesquisa em bancos de dados, sem possibilidade de identificação individual, limitando-se à análise bibliográfica e documental dos arquivos da Anvisa. 


\section{Resultados e Discussão}

No levantamento dos dados obtidos a partir das atas de julgamento da Diretoria Colegiada da Anvisa no ano de 2015, apurou-se que foram proferidas decisões colegiadas acerca de 651 processos administrativos-sanitários oriundos da fiscalização em PAF. Destes, 128 tiveram suas decisões iniciais totalmente reformadas, o equivalente a $19,66 \%$. No ano de 2016, foram decididos pela Diretoria Colegiada 295 processos, dos quais $78(26,44 \%)$ tiveram as decisões reformadas em sua totalidade. A tabela a seguir organiza os processos cujas decisões foram integralmente reformadas conforme as razões para tanto, separadas entre as que atingiram somente a decisão inicial e as que culminaram no arquivamento dos autos.

Tabela 1. Quantidade de processos cujas decisões foram totalmente reformadas, conforme os fundamentos para a reforma

\begin{tabular}{llccc}
\hline & \multicolumn{1}{c}{ Fundamentos para a reforma total } & 2015 & 2016 & Total \\
\hline Decisão & Ausência de Individualização da pena & 54 & 30 & 84 \\
anulada & Ausência de manifestação do servidor autuante & 3 & 6 & 9 \\
& Ausência de consideração do porte econômico & - & 1 & 1 \\
Processo & Prescrição intercorrente & 19 & 2 & 21 \\
arquivado & Prescrição da ação punitiva & - & 1 & 1 \\
& Nulidade da notificação do auto de infração com & 3 & 3 & 6 \\
& Ausência de manifestação do servidor autuante com & - & 1 & 1 \\
& Atipicidade da conduta & 29 & 23 & 52 \\
& Ilegitimidade passiva & 7 & 2 & 9 \\
& Conduta genérica & 7 & 4 & 9 \\
& Excludente de imputabilidade & 5 & 1 & 4 \\
& Autuado demonstrou que sua conduta não interferiu na & 3 & 1 & 3 \\
Ausência de colheita de amostra em triplicata & 2 & - & 1 \\
& Ausência de análise de contraprova & 1 & 1 & 1 \\
Ausência de comprovação da materialidade & - & - & 1 \\
Desproporcionalidade na lavratura do auto de infração & 1 & - & 1 \\
Ocorrência de bis in idem & - & 1 & 1 \\
Inobservância da dupla visita (LC 123) & - & 1 & 1 \\
\hline Total de processos & 128 & 78 & 206
\end{tabular}

Fonte: Elaborada pela autora a partir de dados extraídos dos pareceres contidos nos arquivos da Coordenação de Instrução e Análise de Recurso da Inspeção e da Fiscalização - Corif 
Apurou-se que, dos 206 processos que tiveram suas decisões totalmente reformadas pela Diretoria Colegiada nos anos de 2015 e 2016, em 94 a decisão inicial foi tornada nula e determinou-se que a área julgadora procedesse a novo julgamento. Os 112 restantes foram atingidos em sua integralidade, tendo sido determinado 0 arquivamento dos autos do processo.

Nos 94 casos em que foi determinada a prolação de nova decisão inicial, tem-se que em 84 processos verificou-se a necessidade de individualização da penalidade de multa inicialmente aplicada, a fim de resguardar os direitos ao contraditório e à ampla defesa, garantidos constitucionalmente. Em 9 processos constatou-se que não havia adequada manifestação do servidor autuante quanto às razões apresentadas pelo autuado, consoante determina o artigo 22, $\S 1^{\circ}$, da Lei 6.437/77, e em 1 deles não foi considerado corretamente o porte econômico do autuado, nos termos do artigo $2^{\circ}$, $3^{\circ}$, da Lei $6.437 / 77$.

Já dentre os 112 processos em que a reforma total da decisão inicial atingiu todos os atos do processo, culminando no arquivamento dos autos, tem-se que a prescrição foi declarada em 29 deles. Destes, 6 foram arquivados em decorrência do reconhecimento da nulidade da notificação do infrator quanto à lavratura do auto de infração sanitária, havendo impossibilidade de realização de nova notificação em razão do decurso do tempo e da incidência da prescrição da ação punitiva, ao passo que 1 deles o foi em razão da declaração de nulidade da decisão proferida em primeira instância administrativa em razão da ausência de manifestação do servidor autuante, também se observando ausência de tempo hábil à prolação de nova decisão. Dos demais, 21 foram arquivados em razão da verificação da ocorrência da prescrição intercorrente, e 1 pela incidência da prescrição da pretensão punitiva da Administração Pública, nos termos do artigo $1^{\circ}$ da Lei 9.873/99.

Dos 83 demais processos que foram arquivados em decorrência da reforma total da decisão inicial pelo colegiado da Agência, 52 o foram por constatação de atipicidade da conduta do autuado; 9 por ilegitimidade do autuado para figurar no polo passivo da autuação; 9 por descrição de conduta de forma genérica no auto de infração, impossibilitando o pleno exercício do direito de defesa; 4 por incidência de excludente de culpabilidade, prevista no artigo $3^{\circ}, \S^{\circ}{ }^{\circ}$, da Lei $6.437 / 77 ; 3$ por demonstração por 
parte do autuado, posterior à lavratura do auto, de que sua conduta não interferiu nos padrões de qualidade, segurança e eficácia do produto; 1 por ausência de colheita de amostra em triplicata, consoante determina o artigo 27 da Lei 6.437/77; 1 por ausência de realização da análise de contraprova prevista no artigo 27, §4ํㅡㄹ da Lei 6.437/77; 1 por impossibilidade de comprovação da materialidade da infração; 1 por entender-se que a lavratura do auto de infração foi desproporcional à conduta; 1 por constatação da ocorrência de bis in idem, tendo em vista a existência de outro auto de infração com mesmo objeto; e 1 pela inobservância do critério de dupla visita previsto na Lei Complementar 123/2006, que institui o Estatuto Nacional da Microempresa e da Empresa de Pequeno Porte.

Pelos dados apresentados, observa-se que, das reformas totais realizadas pela Diretoria Colegiada em 2015 e 2016 nos processos de auto de infração de PAF (206 processos), em 94 processos a nulidade atingiu tão somente a decisão inicial, e não todos os atos do processo. Assim sendo, o ato, no caso a decisão inicial, poderia ser, em princípio, novamente realizado, desta vez sem os vícios que inicialmente o maculavam.

Trata-se, portanto, de entendimento pela nulidade da decisão inicial, e não pela anulabilidade, pois se 0 ato fosse refeito nos mesmos moldes (sem individualização da pena, sem observância do porte econômico do infrator e sem manifestação prévia do servidor autuante), incidiria novamente o vício anteriormente constatado. Entende-se, portanto, pela impossibilidade de convalidação do ato, sendo necessária a declaração de nulidade da decisão inicial para prolação de nova decisão, observando-se os preceitos legais. Tal entendimento tem sido partilhado pela Diretoria Colegiada da Anvisa, que em todos os casos têm decidido pela declaração de nulidade da decisão inicial, jamais admitindo a possibilidade de convalidação.

Da mesma forma ocorre com os processos que foram totalmente fulminados em razão da existência de vício de legalidade (112 processos). Excetuando-se os casos em que foi constatada a prescrição intercorrente ou a prescrição da ação punitiva (29 processos) e em que não foi possível a comprovação da materialidade da infração (1 processo), nos quais não se tem resolvido o mérito da questão, em todos os demais casos entendeu-se pela nulidade do auto de infração sanitária. Em casos tais, há de se 
reconhecer a nulidade do ato em razão da constatação de vício de legalidade, não havendo que se falar em possibilidade de convalidação. O auto de infração sanitária, enquanto peça inaugural que visa a cientificar o autuado acerca da instauração do processo administrativo para apuração da infração sanitária, deve seguir estritamente os preceitos legais a fim de possibilitar o pleno exercício do contraditório e da ampla defesa.

Nos casos que foram arquivados em decorrência da nulidade do auto de infração, cabe destacar, em razão de sua maior frequência, a atipicidade da conduta (52 processos), a ilegitimidade passiva (9 processos) e a descrição de conduta genérica (9 processos). A atipicidade da conduta, que representa o maior universo, decorre de um equívoco na interpretação do agente autuante quanto à configuração da infração sanitária. Em tais casos, o auto de infração sequer deveria ter sido lavrado, uma vez que a conduta do autuado não configura infração à legislação sanitária. É possível considerar que também os casos de verificação da ilegitimidade do autuado para figurar no polo passivo da autuação caracterizam equivocada interpretação da norma sanitária pelo agente fiscalizador, neste caso quanto à responsabilização do agente pela infração.

Já nos casos de conduta genérica, tem-se a anulação do auto de infração sanitária em razão da ausência de adequada descrição da conduta de forma a permitir que o autuado se defenda plenamente, como lhe é assegurado constitucionalmente. Em tais situações, não se resolve o mérito da questão, sendo impossível dizer se tais processos culminariam na confirmação ou não da ocorrência da infração sanitária. Tem-se, portanto, a declaração de nulidade do auto de infração por existência de erro formal, o qual poderia ser evitado caso a descrição da conduta fosse feita de forma adequada e minuciosa.

Portanto, dos dados obtidos observa-se que alguns dos fundamentos identificados para a reforma total das decisões podem ser incluídos nas hipóteses inicialmente aventadas. A atipicidade da conduta e a ilegitimidade passiva do autuado podem ser consideradas como fatores relacionados à equivocada interpretação da norma sanitária pelo agente autuante (hipótese a), uma vez que caso a norma tivesse sido adequadamente entendida pelo fiscal a autuação jamais teria ocorrido, ou teria se dado em desfavor da parte legítima para responder pela infração sanitária. A descrição da 
conduta de maneira genérica enquadra-se na hipótese de erro formal no preenchimento do auto (hipótese b), visto que se tem a ausência de adequada e pormenorizada descrição da infração no documento inaugural do processo administrativo sanitário, o qual visa justamente dar plena ciência ao autuado da infração que está sendo a ele imputada. Por fim, a ausência de comprovação da materialidade da infração pode ser incluída na hipótese de má instrução processual (hipótese c), considerando-se que o motivo da reforma total foi a impossibilidade de demonstração da real ocorrência da infração sanitária a partir dos documentos acostados aos autos.

\section{Considerações Finais}

Pela análise dos dados apresentados, observa-se que as hipóteses inicialmente levantadas foram parcialmente confirmadas. A interpretação equivocada da norma sanitária pelo agente autuante (hipótese a) revelou-se um importante fator para a reforma total das decisões pela Diretoria Colegiada, consistindo em 61 processos ou 29,6\% do total, considerando-se o enquadramento em tal categoria da autuação por conduta atípica e da autuação de parte ilegítima. A existência de erro formal no preenchimento do auto de infração (hipótese b) também foi encontrada como motivo para a reforma total, embora com menor expressividade, enquadrando-se em tal categoria a descrição de conduta de forma genérica, equivalente a 9 processos $(4,37 \%)$. Já a má instrução processual foi responsável pela reforma total de apenas 1 decisão $(0,49 \%)$, sabidamente aquela em que não ficou comprovada nos autos a materialidade da infração. Por outro lado, observa-se que outros fundamentos se mostraram relevantes para que a Diretoria Colegiada decidisse pela reforma total da decisão, em especial a ausência de individualização da pena (40,78\%) e a prescrição $(14,08 \%)$.

Verifica-se nos resultados apurados que em todos os casos a reforma total da decisão inicial pela Diretoria Colegiada da Anvisa tem sido realizada reconhecendo-se a nulidade do ato administrativo prévio, seja ele a própria decisão inicial ou a peça inaugural do processo administrativo sanitário. Assim, dentre os casos ora apreciados não se observou nenhum em que pudesse ser realizada a convalidação do ato, até mesmo em razão da importância dos vícios verificados, todos eles relacionados à legalidade do ato e, em especial, à necessidade de observância do direito ao 
contraditório e à ampla defesa. Tem-se, portanto, que a declaração de nulidade realizada pelas decisões da Diretoria Colegiada opera efeitos ex tunc, retroagindo à data do ato declarado nulo. Assim, anulam-se todos os atos que se seguiram ao ato anulado, o qual deixa de produzir seus efeitos.

Em grande parte dos casos em que é constatada a infração sanitária em PAF e, portanto, lavrado o auto respectivo, são também lavrados diversos outros termos oriundos da fiscalização sanitária. Quanto a este aspecto, destacamos os casos de infração sanitária detectada durante a importação de produtos submetidos à vigilância sanitária. A depender da infração sanitária constatada, frequentemente faz-se necessária a interdição cautelar da mercadoria, a fim de se prevenir a ocorrência de riscos à saúde, determinando-se, por fim, sua destinação final, que pode ser o retorno ao exterior ou a destruição no país, nos termos da legislação de regência do tema.

Conforme exposto, as medidas cautelares visam à proteção da saúde da população contra riscos iminentes, e devem ser prontamente adotadas pela fiscalização, com base no princípio da prevenção que deve orientar as ações de vigilância sanitária. No entanto, os processos administrativos-sanitários para a apuração de infrações, por vezes, arrastam-se por anos até sua conclusão com a decisão em última instância pela Diretoria Colegiada.

Assim, observam-se casos em que, após havida a destruição da carga por determinação da Agência em procedimento cautelar, verifica-se a nulidade do auto de infração por atipicidade da conduta do autuado, por exemplo, situação em que se afasta a responsabilidade do autuado pela infração. Discute-se, portanto, se haveria no citado caso a possibilidade de indenização do administrado em decorrência do perdimento da carga. Saliente-se que aqui não se trata da possibilidade de indenização em razão da própria anulação do ato administrativo (auto de infração sanitária), conforme expõe a doutrina acerca do tema, mas sim da possibilidade de indenização em decorrência de outro ato adotado cautelarmente pela Administração Pública em razão do mesmo fato. Contudo, entende-se possível a aplicação analógica dos entendimentos doutrinários acerca do tema. Assim, havendo o administrado agido de boa-fé e comprovados os prejuízos decorrentes da atuação da Anvisa em procedimento cautelar, seria possível, em princípio, a indenização do autuado. 
Frise-se, contudo, que tal possibilidade somente seria possível nos casos em que a reforma total da decisão se desse pela declaração de nulidade do auto de infração reconhecendo-se a inexistência da ocorrência de infração sanitária, destacando-se os casos de atipicidade da conduta. A título de exemplo, cite-se uma importação tida por irregular por ausência de informação considerada essencial na rotulagem do produto em que teria sido determinada a destinação final da carga, e quando da conclusão do processo administrativo sanitário fosse verificada a existência de norma sanitária que dispensasse a obrigatoriedade de tal informação na rotulagem do produto. Estando o autuado de boa-fé, em tal caso seria possível, em tese, sua indenização pelos danos decorrentes do perdimento dos bens.

Tendo em vista a importância da fiscalização sanitária realizada em portos, aeroportos e fronteiras para a proteção da saúde da população e dos viajantes, faz-se necessário o seu contínuo aperfeiçoamento e fortalecimento. E uma das formas de fazêlo é capacitando os agentes que ali atuam para identificar e conter riscos com maior precisão e rapidez, bem como para agir com maior perícia nos casos em que se faz necessária a repressão de condutas contrárias às normas sanitárias.

Conforme os dados apresentados, tem-se que um significativo percentual (quase $20 \%$ em 2015 e mais de 25\% em 2016) dos processos julgados pela Diretoria Colegiada tiveram suas decisões totalmente reformadas, representando a existência de graves falhas no procedimento administrativo para a apuração de infrações sanitárias em PAF, seja no momento da lavratura do auto de infração, seja no desenrolar do processo. Vêse, portanto, a necessidade de aprimoramento das técnicas e procedimentos adotados pela Agência para uma maior eficácia na fiscalização de PAF, de forma a melhor resguardar a saúde dos viajantes e da população.

\section{Referências}

1. Brasil. Constituição da República Federativa do Brasil de 1988. Diário Oficial da União. Brasília, 5 out 2010. Disponível em: http://www.planalto.gov.br/ccivil_03/constituicao/constituicaocompilado.htm; [Acesso em 17.set.2017].

2. Brasil. Lei no 8.080 , de 19 de setembro de 1990. Dispõe sobre as condições para a promoção, proteção e recuperação da saúde, a organização e o funcionamento dos serviços correspondentes e dá outras providências. Diário Oficial da União. 
Brasília, 20 set 1990. Disponível em:

http://www.planalto.gov.br/ccivil_03/leis/L8080.htm; [Acesso em 17.set.2017].

3. Dias HP. Flagrantes do Ordenamento Jurídico-Sanitário. 3.ed. Brasília: Anvisa, 2008.

4. Costa EA. Vigilância Sanitária: proteção e defesa da saúde. 2.ed. aumentada. São Paulo: Sociedade Brasileira de Vigilância de Medicamentos, 2004.

5. Brasil. Lei no 9.782, de 26 de janeiro de 1999. Define o Sistema Nacional de Vigilância Sanitária, cria a Agência Nacional de Vigilância Sanitária, e dá outras providências. Brasília, 27 jan 1999. Disponível em:

http://www.planalto.gov.br/ccivil_03/leis/L9782.htm; [Acesso em 16.set.2017].

6. Oliveira MGR. Reflexões sobre o modelo de fiscalização sanitária nos portos, aeroportos e fronteiras do Brasil. Caderno Ibero-americanos de Direito Sanitário. Jan/mar 2015; 4 (1):3-11. Disponível em:

http://www.cadernos.prodisa.fiocruz.br/index.php/cadernos/article/view/188/194; [Acesso em 15.set.2017].

7. Brasil. Decreto 8.077/2013, de 14 de agosto de 2013. Regulamenta as condições para o funcionamento de empresas sujeitas ao licenciamento sanitário, e o registro, controle e monitoramento, no âmbito da vigilância sanitária, dos produtos de que trata a Lei $n^{\circ} 6.360$, de 23 de setembro de 1976, e dá outras providências. Brasília, 15 ago 2013. Disponível em:

http://www.planalto.gov.br/ccivil_03/_ato2011-2014/2013/decreto/d8077.htm; [Acesso em 12.nov.2017].

8. Brasil. Lei no 6.360, de 23 de setembro de 1976. Dispõe sobre a Vigilância Sanitária a que ficam sujeitos os Medicamentos, as Drogas, os Insumos Farmacêuticos e Correlatos, Cosméticos, Saneantes e Outros Produtos, e dá outras Providências. Brasília, 24 set 1976. Disponível em: http://www.planalto.gov.br/ccivil_03/leis/L6360.htm; [Acesso em 12.nov.2017].

9. Brasil. Decreto n 79.094 , de 5 de janeiro de 1977. Regulamenta a Lei no 6.360, de 23 de setembro de 1976, que submete a sistema de vigilância sanitária os medicamentos, insumos farmacêuticos, drogas, correlatos, cosméticos, produtos de higiene, saneamento e outros. Brasília, 7 jan 1977. Disponível em: http://www.planalto.gov.br/ccivil_03/decreto/antigos/d79094.htm; [Acesso em 12.nov.2017].

10.Brasil. Lei no 6.437, de 20 de agosto de 1977. Configura infrações à legislação sanitária federal, estabelece as sanções respectivas, e dá outras providências. Diário Oficial da União. Brasília, 24 ago 1977. Disponível em: http://www.planalto.gov.br/ccivil_03/leis/L6437.htm; [Acesso em 16.set.2017].

11. Carvalho C, Machado RB, Timm LB. Direito Sanitário Brasileiro. São Paulo: Quartier Latin, 2004. 
12. Mello CAB. Curso de Direito Administrativo. 30.ed. São Paulo: Malheiros Editores, 2013.

13. Brasil. Agência Nacional de Vigilância Sanitária. Resolução da Diretoria Colegiada-RDC $n^{\circ} 61$, de 3 de fevereiro de 2016. Diário Oficial da União. Aprova e promulga o Regimento Interno da Agência Nacional de Vigilância Sanitária ANVISA e dá outras providências. Brasília, 5 fev 2016. Disponível em: http://portal.anvisa.gov.br/documents/281258/281284/Regimento+Interno+da+Anv isa+-+RDC+n\%C2\%BA+61+de+2016/07ccbb20-f3b3-4209-bf84-f520a1a29eab; [Acesso em 16.set.2017].

14.Brasil. Lei $n^{0} 9.784$, de 29 de janeiro de 1999. Regula o processo administrativo no âmbito da Administração Pública Federal. Diário Oficial da União. Brasília, 1ํㅜ fev 1999. Disponível em: http://www.planalto.gov.br/ccivil_03/leis/L9784.htm; [Acesso em 16.set.2017].

15. Moreira EB. Processo Administrativo: Princípios Constitucionais e a Lei 9.784/1999. 3.ed. São Paulo: Malheiros Editores, 2007.

16. Cartana AP. Processo Administrativo Sanitário: teoria e prática. Porto Alegre: Alcance, 2000.

17.Gasparini D. Direito Administrativo. 17.ed. São Paulo: Saraiva, 2012.

18. Carvalho Filho JS. Processo Administrativo Federal: comentários à Lei no 9.784, de 29.1.1999. 5.ed. São Paulo: Atlas, 2013.

19. Medauar O. Direito Administrativo Moderno. 18.ed. São Paulo: Revista dos Tribunais, 2014.

20.Meirelles, HL. Direito Administrativo Brasileiro. 39.ed. São Paulo: Malheiros, 2013.

21.Brasil. Lei no 9.873, de 23 de novembro de 1999. Estabelece prazo de prescrição para o exercício de ação punitiva pela Administração Pública Federal, direta e indireta, e dá outras providências. Brasília, 24 nov 1999. Disponível em: http://www.planalto.gov.br/ccivil_03/leis/L9873.htm; [Acesso em 12.nov.2017].

Recebido em: 25.11.2017

Aprovado em: 26.12.2017

\section{Como citar este artigo:}

Albuquerque ALZL. Os fundamentos para a reforma total das decisões recursais proferidas em processos de auto de infração sanitária em portos, aeroportos e fronteiras. Revista Cadernos Ibero-Americanos de Direito Sanitário. 2017 out./dez, 6(4):91-111. 